\begin{tabular}{|c|c|c|}
\hline ב & $\begin{array}{c}\text { International Journal of Current Research } \\
\text { and Academic Review }\end{array}$ & \\
\hline $\begin{array}{l}\text { EXCELLENT } \\
\text { PUBLISHERS }\end{array}$ & $\begin{array}{l}\text { ISSN: 2347-3215 (Online) Volume } 6 \text { Number } 4 \text { (April-2018) } \\
\text { Journal homepage: http://www.ijcrar.com }\end{array}$ & \\
\hline
\end{tabular}

doi: https://doi.org/10.20546/ijcrar.2018.604.009

\title{
Domestic Food Hygiene Practices in a Rural Area of Thrissur District, Kerala, India
}

\author{
Bablu Raphael ${ }^{1}$, N. Catherin ${ }^{2 *}$, C. J. Navya ${ }^{2}$ and C. R. Saju ${ }^{2}$ \\ ${ }^{1}$ Department of Community Medicine, Al Azar Medical College, Thodupuzha, Kerala, India \\ ${ }^{2}$ Department of Community Medicine, Amala Institute of Medical Sciences, Thrissur, Kerala, India \\ *Corresponding author
}

\section{Abstract}

Unsafe food has been a human health problem since history was first recorded, and many food safety problems encountered today are not new. More than 200 known diseases are transmitted through food. The chances of food contamination and cross-contamination become higher, especially in the lower socio-economic classes due to unsatisfactory environmental conditions, poor personal hygiene, poor quality and insufficient water supplies, unhygienic preparations, storage and feeding of foods. To find out the food hygiene practices of household food-handlers in a rural area of Thrissur district, Kerala, India. A community based cross-sectional study was conducted from November 2014 to April 2015 among 80 household food-handlers in a rural area of Thrissur district. A pre-tested semi-structured questionnaire based on WHO (World Health Organization) Food Safety Manual was used to collect data regarding kitchen and food hygiene practices. The study revealed that only less than half 37 (46\%) had the desirable habit of always washing their hand before and during food preparation. Although majority $70(87.5 \%)$ used to store raw and cooked foods separately, only less than half $39(49 \%)$ used separate utensils and cutting boards for preparing raw and cooked foods. The results of the study showed that food hygiene practices should be improved in the community to safe guard them against food-borne diseases.
\end{abstract}

\section{Article Info}

Accepted: 30 March 2017

Available Online: 20 April 2018

\section{Keywords}

Food handlers,

Food hygiene practices,

Food safety manual

\section{Introduction}

Unsafe food has been a human health problem since history was first recorded, and many food safety problems encountered today are not new. Although governments all over the world are doing their best to improve the safety of the food supply, the occurrence of food-borne disease remains a significant health issue in both developed and developing countries. It has been estimated that each year 1.8 million people die as a result of diarrheal diseases and most of these cases can be attributed to contaminated food or water. Proper food preparation can prevent most food borne diseases (Five keys to safer food manual). More than 200 known diseases are transmitted through food. (Mead et al., 1985).

The chances of food contamination and cross contamination, become higher especially in the lower socio-economic classes due to unsatisfactory environmental conditions, poor personal hygiene, poor quality and insufficient water supplies, unhygienic preparation storage and feeding of foods. (Khan Hameed, 1997; Lal et al., 1996; Rowan et al., 1997; UNICEF, 2000). Contaminated food presents one of the most common cause and major contributor to gastrointestinal 
illness (e.g. acute diarrhea, nausea, vomiting and abdominal pain), compromised nutritional status and less resistance to disease and loss of productivity in the world today (Jacob, 1989). To a large extent gastrointestinal illness resulting from food contamination can be prevented if safe food-hygiene practices are followed at various stages of food purchase, storage, preparation and consumption (Mathee et al., 2004).

The World Health Organization (WHO) has long been aware of the need to educate food handlers about their responsibilities for food safety. In the early 1990s, WHO developed the Ten Golden Rules for Safe Food Preparation and introduced the Five Keys to Safer Food in 2001. Recognizing the importance of safe food in human health, WHO has selected the theme of Food Safety for the World Health Day, 2015, with the objective of ensuring safety of food from farm to plate. Barring a few studies, little has been reported about the food hygiene practices in the community in India, and none so ever in Kerala (Mini Sheth and Monika Obrah, 2004; Sudershan et al., 2008). The objective of this study was to find out the food hygiene practices of house hold food handlers in a rural area in Thrissur district of Kerala, India.

\section{Materials and Methods}

A community based cross sectional study was conducted among house hold food handlers Thrissur district, Kerala, India. The calculated sample size based on prevalence of separating utensils for raw and cooked foods was 80 (Kumiko Takanashi et al., 2009). From the 18 wards in a panchayat one ward was selected randomly by lottery method. From the selected ward, 80 households were selected by systematic random sampling. From each of the selected households, the person predominantly involved in food handling was selected for the study. A semi-structured questionnaire was used to collect data regarding socio-demographic characteristics, general sanitation practices and food hygiene practices based on the WHO Food Safety Manual. (Five Keys to Safer Food Manual, 2006)

\section{Results and Discussion}

Out of the 80 participants in the study, $16(20 \%)$ were males and $64(80 \%)$ were females. Mean age was $48.5+$ 12.5. Majority $62(77.5 \%)$ were Hindu by religion. 42 (52.5\%) belonged to APL category. 26 (32.5\%) were educated up to high school level. Most of the participants $35(43.75 \%)$ were homemakers (Table 1$)$.
In the study population 66 (82.5\%) used boiled water for drinking. $66(82.5 \%)$ of the respondents used to add unboiled water to boiled drinking water. 23 (28\%) said that their fingers would touch the stored drinking water during fetching.

Among those who owned a fridge $43(67 \%)$ used unboiled water for making ice used in beverages. 8 respondents (10\%) allowed pet animals to enter the kitchen. 33 respondents $(41 \%)$ did not have a waste basket in the kitchen, and out of them, only 9 respondents (19\%) had a covered and foot operated waste basket (Table 2).

Out of the 80 respondents, only 37 respondents (46.0\%) always used to wash their hands before and during food preparation. $58(72 \%)$ always used to clean utensils used for food preparation before using for other food items.

While 39 (48.0\%) always used separate utensils and cutting boards for raw and cooked foods, $15.0 \%$ (12) never used separate utensils for raw and cooked foods.

Out of the 64 respondents who owned a refrigerator, none of them used to thaw frozen food inside the refrigerator or other cool places (Table 3).

58 respondents ( $90 \%$ of those who owned a refrigerator) did not use to store cooked food in the refrigerator within two hours of cooking. 56 respondents $(87.0 \%)$ used to cover the food inside refrigerator. Out of the 80 respondents, $54(67 \%)$ used to check and throw away food beyond its expiry date. 69 (86\%) always used to wash fruits and vegetables in safe water before eating them (Table 4).

The present study revealed that only $82 \%$ of the respondents used boiled water for drinking, and $82 \%$ used to add un-boiled water to the boiled drinking water. This could be due to the lack of awareness about the risk of contamination of boiled water by adding unboiled water.

Among those who owned a refrigerator, 67\% used unboiled water to make ice used for edible purposes. This practice is considered hazardous to health as the quality of un-boiled water is not reliable in India. In a study conducted in Hyderabad, it has been found that those who did not boil water consistently before drinking had a high prevalence rate of Helicobacter pylori infection in addition to the usual water-borne enteric infections (Ahmed et al., 2007). 
Table.1 Demographic characteristics of the study population

\begin{tabular}{|l|l|}
\hline \multicolumn{1}{|c|}{ Demographic characteristics } & \multicolumn{1}{|c|}{ Frequency $[\mathrm{N}=80] \mathrm{N}(\%)$} \\
\hline Gender & $16(20 \%)$ \\
Males & $64(80 \%)$ \\
Females & $38(47.5 \%)$ \\
Socioeconomic status & $42(52.5 \%)$ \\
APL & \\
BPL & $4(5 \%)$ \\
Education & $7(8.75 \%)$ \\
Professional & $12(15 \%)$ \\
Graduate & $26(32.5 \%)$ \\
Higher secondary & $11(13.75 \%)$ \\
High school & $20(25 \%)$ \\
Upper primary & \\
Lower primary & \\
\hline
\end{tabular}

Table.2 Sanitary conditions of the study population

\begin{tabular}{|l|l|}
\hline \multicolumn{2}{|c|}{ Conditions of sanitation } \\
\hline Water source & $62(77.5 \%)$ \\
Own well & $6(7.5 \%)$ \\
Panchayat well & $12(15 \%)$ \\
Panchayat pipe & $66(82.5 \%)$ \\
Boiling drinking water & $14(17.5 \%)$ \\
Yes & \\
No & $66(82.5 \%)$ \\
Adding un-boiled water to boiled drinking water & $14(17.5 \%)$ \\
Yes & \\
No & $76(95 \%)$ \\
Keeping drinking water covered & $4(5 \%)$ \\
Yes & \\
No & \\
Regular (daily) washing of the utensil in which & \\
drinking water is kept & $74(92.5 \%)$ \\
Yes & $6(7.5 \%)$ \\
No & \\
Touching drinking water in the pot with fingers & \\
while collecting & $23(28.75 \%)$ \\
Yes & $57(71.25 \%)$ \\
No & \\
Type of water used for making ice [n =64] & $21(32.8 \%)$ \\
Boiled water & $43(67.2 \%)$ \\
Un-boiled water & \\
Have waste basket in the kitchen & $47(58.75 \%)$ \\
Yes & $33(41.25 \%)$ \\
No & $15(31.9 \%)$ \\
Type of waste basket [n =47] & $23(48.9 \%)$ \\
Uncovered & $9(19.1 \%)$ \\
Covered & \\
\hline
\end{tabular}


Table.3 Food hygiene practices among the study population

\begin{tabular}{|l|l|}
\hline Food hygiene practice & Frequency \\
\hline Washing hands before and during food preparation & \\
Always & $37(46.25 \%)$ \\
Most times & $30(37.50 \%)$ \\
Sometimes & $9(11.25 \%)$ \\
Never & $4(5 \%)$ \\
Cleaning surfaces and utensils used for food preparation before using on other food & \\
Always & $58(72.5 \%)$ \\
Most times & $15(18.75 \%)$ \\
Sometimes & $4(5.0 \%)$ \\
Never & $3(3.75 \%)$ \\
Using separate utensils and cutting boards when preparing raw and cooked food & \\
Always & $39(48.75 \%)$ \\
Most times & $20(25 \%)$ \\
Sometimes & $9(11.25 \%)$ \\
Never & $12(15 \%)$ \\
Separating raw and cooked food during storage & $70(87.5 \%)$ \\
Always & $5(6.25 \%)$ \\
Most times & $1(1.25 \%)$ \\
Sometimes & $4(5 \%)$ \\
Never & \\
\hline
\end{tabular}

Table.4 Food hygiene practices among the study population

\begin{tabular}{|l|l|}
\hline Food hygiene practice & Frequency \\
\hline Reheating cooked food until it is piping hot throughout & \\
Always & $64(80.0 \%)$ \\
Most times & $12(15 \%)$ \\
Sometimes & $1(1.25 \%)$ \\
Never & $3(3.75 \%)$ \\
Thawing frozen food in the refrigerator [n= 64] & $0(0 \%)$ \\
Yes & $64(100 \%)$ \\
No & \\
Storing cooked food in the fridge within two hours $[\mathrm{n}=64]$ & $6(9.37 \%)$ \\
Yes & $58(90.62 \%)$ \\
No & \\
Keeping food covered in the fridge [n $=64]$ & $56(87.5 \%)$ \\
Yes & $8(12.5 \%)$ \\
No & $54(67.5 \%)$ \\
Check and throw away food beyond its expiry date & $15(18.75 \%)$ \\
Always & $5(6.25 \%)$ \\
Most times & $6(7.5 \%)$ \\
Sometimes & \\
Never & $69(86.25 \%)$ \\
Washing fruits and vegetables in safe water before eating them & $8(10 \%)$ \\
Always & $1(1.25 \%)$ \\
Most times & $2(2.5 \%)$ \\
Sometimes & \\
Never &
\end{tabular}


Out of the 80 respondents, $95 \%$ kept drinking water in covered containers and $92.5 \%$ washed the container regularly. But $28.75 \%$ were using unhygienic method to draw water from the container. In a study done in Chandigarh, $88 \%$ of respondents covered their drinking water but nearly half of them used unhygienic method to draw water (Jasvir Kaur et al., 2006). 10\% of the respondents allowed pets in their kitchen and $41.25 \%$ did not have a waste basket in the kitchen. Among those who had a waste basket in the kitchen, $31.9 \%$ had an uncovered waste basket. In the study done in Chandigarh, unclean kitchen was significantly associated with gastrointestinal health complaints (Jasvir Kaur et al., 2006).

Only $46.25 \%$ always washed their hands before and during food preparation. $77.5 \%$ used to clean surfaces and utensils used in food preparation before using on other food items. A study in United States reported that $66 \%$ respondents did not wash hands prior to handling food and majority had inadequately clean kitchen utensils (LiCohen and Bruhm, 2002). In a study done in Baroda, $77 \%$ of mothers had poor personal hygiene including inadequate hand washing while preparing food (Mini Sheth and Monika Obrah, 2004).

While $48 \%$ of respondents always used separate utensils and cutting boards for preparing raw and cooked food items, $15 \%$ never used. $87 \%$ always used to store raw and cooked food separately, while $5 \%$ never used to store them separately. A study reported that $42 \%$ mothers in a sub-urban area of Viet Nam did not use separate utensils for raw and cooked food and this was associated with increased incidence of diarrhea among children (Kumiko Takanashi et al., 2009).

Only $9 \%$ of the respondents used to store cooked food in the refrigerator within two hours of cooking. $87 \%$ said that they always keep food covered in the fridge. $80 \%$ used to reheat cooked food until it is piping hot. But none of the respondents who owned a refrigerator with freezer used to thaw frozen food in the refrigerator. In a study done in Gujarat, 59\% of respondents were unaware about the safe temperatures for heating leftover food for consumption and almost half didn't know about the safe duration of storage of cooked food at room temperature (Shriya et al., 2014). A study in Hyderabad reported that over $60 \%$ stored leftover cooked foods at room temperature (Sudershan et al., 2008). 67\% of the respondents said that they always checked and threw packaged food beyond its expiry date, while $7.5 \%$ never did the same. A study reported that though $48 \%$ of respondents in Hyderabad bought packed foods, majority (78\%) of them did not acknowledge food labels (Sudershan et al., 2008). In the present study, majority (86\%) always used to wash fruits and vegetables in safe water before consuming them. In the study done in Gujarat, most of the respondents (78.9\%) had very good practice of washing fruits and vegetables before use (Shriya et al., 2014).

The present study was conducted to assess the food hygiene practices of domestic food handlers in a rural area of Thrissur, Kerala, India. The study revealed that only less than half $(46 \%)$ had the desirable habit of always washing their hands before and during food preparation. Although majority $(87.5 \%)$ used to store raw and cooked foods separately, only less than half $(48.75 \%)$ used separate utensils and cutting boards for preparing raw and cooked food. The study results showed that food hygiene practices were inadequate in the population. This situation should be improved in the community to safe guard them against food-borne diseases. Creating awareness through health education and involving the community in spreading the message are essential.

\section{References}

Five keys to safer food manual. Department of food safety, zoonoses and food borne diseases. WHO

Mead, P.S., et al., Food-Related Illness and Death in the United States Emerging Infectious Diseases, Vol 5, No. 5, 1999 Raymond Isley B. Primary health care, water supply and sanitation in Africa. World Health Forum 1985; 6: 213-219

Khan Hameed A. The sanitation gap. Development deadly menace: Progress of Nations. UNICF Publications 1997; 5-12

Lal P, Bansal AK, Aggarwal CS, Taneja BK, Gogia V. Incidence of diarrhea and some related environmental and behavioral factors in Jhuggies of Delhi. Ind J Public Health 1996; 40(2): 35- 37

Rowan N, Anderson JG, Anderton A. The bacteriological quality of hospital prepared infants foods. J Hosp Infct 1997; 35(4): 259-267

UNICEF. The state of world's children 2000. Progress report 2000. UNICEF, New Delhi

Jacob M. Safe food handling-A training guide for managers of food service establishments. WHO, Geneva 1989:1-9

Mathee A, Vonschirnding YE, Byrne $\mathrm{J}$ et al., The greater Johanneburg healthy foods/ markets programme. www.ncbi.nih. 
Mini Sheth, and Monika Obrah. Diarrhea Prevention through Food Safety Education. Indian Journal of Pediatrics, Volume 71--October, 2004.

Sudershan, R.V., G.M. Subba Rao, Pratima Rao, M. Vishnu Vardhana Rao, Kalpagam Polasa. Food safety related perceptions and practices of mothers A case study in Hyderabad, India. Food Control, Volume 19, Issue 5, May 2008, Pages 506-513

Kumiko Takanashi1, Yuko Chonan, Dao To Quyen, Nguyen Cong Khan, Krishna C. Poudel, Masamine Jimba. Survey of Food-hygiene Practices at Home and Childhood Diarrhoea in Hanoi, Viet Nam. Journal of Health, Population and Nutrition; October 2009

Five Keys to Safer Food Manual, Department of food safety, zoonoses and foodborne diseases, World Health Organization, 2006

Ahmed K S, Khan A A, Ahmed I, Tiwari S K, Habeeb A, Ahi J D, Abid Z, Ahmed N, Habibullah C M. Impact of household hygiene and water source on

\section{How to cite this article:}

Bablu Raphael, N. Catherin, C. J. Navya and Saju C. R. 2018. Domestic Food Hygiene Practices in a Rural Area of Thrissur District, Kerala, India. Int.J.Curr.Res.Aca.Rev. 6(4), 59-64.

doi: https://doi.org/10.20546/ijcrar.2018.604.009 the prevalence and transmission of Helicobacter pylori: a South Indian perspective Singapore Med J 2007; 48 (6): 543

Jasvir Kaur, Inderjit Walia, Amarjit Singh, Kavita Gauri. An exploratory study on association between foodhygiene practices and gastrointestinal health complaints among a rural population of U.T., Chandigarh, 2005. Nursing and Midwifery Research Journal, Vol-2, No. 1, January 2006

LiCohen AE, and Bruhm CM, Safety of consumer handling of food produce from the time of purchase to the plate a comprehensive consumer survey. J. ford Prof. 2002; 65(8): 1287-1296.

Shriya A. Seksaria, Mini K. Sheth. Maternal Knowledge and Practices towards Sanitation and Their Relationships with Occurrence of Diarrhoea in Children. International Journal of Public Health Science (IJPHS) Vol.3, No.3, September 2014, 206 212 